ISSN: 2224-0616

Int. J. Agril. Res. Innov. Tech. 9(1): 1-7, June 2019

DOI: https://doi.org/10.3329/ijarit.v9i1.42942

Available online at http://ijarit.webs.com https://www.banglajol.info/index.php/IJARIT

\title{
MUTATION DETERMINATION OF RICE BY USING RAPD PRIMERS
}

\author{
M.S.H. Bhuiyan ${ }^{*}$, M.A. Malek ${ }^{2}$, S.H. Bhuiyan ${ }^{3}$, M. Islam ${ }^{4}$ and A.B.A. Hassan5
}

Received 21 December 2018, Revised 14 May 2019, Accepted 24 June 2019, Published online 30 June 2019

\begin{abstract}
PCR is a powerful tool for the amplification of genetic sequences but sometimes, even though using an established PCR protocol that had been optimized and successful for the amplification of a particular DNA segment, use of that same protocol on a different region can result in a less than desirable outcome. Therefore, an experiment was conducted at Molecular biology laboratory of Malaysian Nuclear Agency during December 2016 to January 2017 used seeds of 6 indica rice cultivars. To conduce RAPD experiments for the rice species it was established the following reaction conditions for the final volume of $20 \mu \mathrm{l}$ where 0.1 unit of Taq DNA polymerase, $0.4 \mu \mathrm{l}$ of each dNTP, $2.5 \mathrm{mM} \mathrm{MgCl} 2,1 \mu \mathrm{l}$ primer and 2.o $\mu \mathrm{l}$ of DNA template. From this experiment, it is clear that after mutation the parent MR219 performed some genetic modification and produce genetically different variety namely NMR151, NMR152, ML3, ML10 and ML30. These mutant varieties have two different groups based on their mutation source and it is clear enough from their RAPD profile.
\end{abstract}

Keywords: RAPD Primers, Mutation Source, Primer Optimization and Rice

${ }^{1}$ Scientific Officer, Plant Breeding Division, Bangladesh Institute of Nuclear Agriculture. Mymensingh, Bangladesh.

${ }^{2}$ Chief Scientific Officer, Plant Breeding Division, Bangladesh Institute of Nuclear Agriculture. Mymensingh, Bangladesh.

${ }^{3}$ Principal Scientific Officer, Electronics \& Health Physics, Bangladesh Institute of Nuclear Agriculture. Mymensingh,

Bangladesh.

${ }^{4}$ Scientific Officer, Bangladesh Institute of Nuclear Agriculture. Sub-Station Sunamganj, Bangladesh.

${ }^{5}$ Research Officer, Malaysian Nuclear Agency, MNA, Malaysia.

*Corresponding author's email: saikat.ag88@gmail.com (M.S.H. Bhuiyan)

Cite this article as: Bhuiyan, M.S.H., Malek, M.A., Bhuiyan, S.H., Islam, M. \& Hassan, A.B.A. (2019). Mutation determination of rice by using RAPD primers. Int. J. Agril. Res. Innov. Tech. 9(1), 1-7.

\section{Introduction}

The challenge of feeding the expected 9 billion world population by 2050 in a sustainable manner can be met, among other measures, by rescuing and using more diversity in agricultural and food production systems, both in terms of crop as in terms of varieties within any given crop (Anumalla et al., 2015). Present day agriculture attributed with the both inter- and intra-specific reduced crop plants diversity. It was estimated that today's amongst the approximately 30 thousand crop species, the human population today derives most of its calories from only 30 species known to feed the world, with the three top most cereal crops: rice, wheat and maize and those species providing $95 \%$ of the global food energy. Nearly 482 million metric tons of husked rice produced in the last harvesting year worldwide. Traditionally, countries in Asia have the largest share in world rice production. According to the most recent official data, with a production volume of over 210 million metric tons in 2017 (https://www.statista.com), China was the world's leading paddy rice producer, followed by India. In this adverse period, plant breeding contributes to diminution of the plant diversity through the development of adapted breeding populations with higher biological yield, potential best genotypes selection, genotypic homogeneous cultivars development and promotion of few widely adapted varieties (Haussmann et al., 2004). The basis for raising crop production and improving crop quality is to breed new varieties. The key to breed new varieties is largely depended on the breakthrough of mining the plant germplasm resources. Mutation breeding is the purposeful application of mutations in plant breeding. Unlike hybridization and selection, mutation breeding has the advantage of improving a defect in an otherwise elite cultivar, without losing its agronomic and quality characteristics. Ionizing radiation used exclusively in mutation research until the effects of certain chemicals on the DNA published in the mid-1940s. In the beginning, X- 
rays used, but $\gamma$-rays from radioactive sources such as ${ }^{60} \mathrm{Co}$ and ${ }^{137 \mathrm{Cs}}$ became popular. Ion beams induce mutations have higher frequency and now used for mutation source. How the various sources perform on the same object is very interesting. It can be observed by phenotypically or using molecular marker. Among molecular marker systems used to identify and assess the genetic diversity and phylogenetic relationships in plant genetic resources, random amplified polymorphic DNA (RAPD) technique developed by Williams et al. (1990) is the fastest and simplest. In rice, RAPD analysis has extensively used for many purposes including identification and classification of germplasm (Choudhury et al., 2001, Ravi et al., 2003) identification of duplicate rice accession in germplasm collection (Virk et al., 1995) and predicting quantitative variation within germplasm (Virk et al., 1996).

Random amplified polymorphic DNA (RAPD) is a PCR-based marker system in which the total genomic DNA is amplified using a single short random primer. It differs from traditional PCR analysis in that it does not require specific knowledge of the DNA sequence of the target organism (arbitrary sequence). The primer will or will not amplify a segment of DNA, depending on whether the positions are complementary to the primer's sequence. Consequently, if a mutation has occurred in the template DNA at the site that used to be complementary to the primer, no amplification will occur to produce a PCR product, resulting in a different electrophoretic mobility pattern for the amplified DNA segments.
RAPD markers are mostly dominant markers (impossible to distinguish between DNA amplified from a heterozygous locus or homozygous locus). Further, the results of an assay is laboratory dependent, influenced by the concentration of the template DNA and PCR parameters and cycling conditions (i.e., they are very difficult to reproduce). This method yields high levels of polymorphism and is simple and quick to conduct. When using RAPD markers, using only the reproducible major bands for identification may minimize its shortcomings. Further, parental genomes may be included where available to help determine bands of genetic origin. Therefore, this simple experiment was conducted to fulfill the following objectives:

- To find out the genetic variation between parent and there mutant variety and

- To understand the effect of mutation source on rice breeding.

\section{Materials and Methods}

\section{Plant materials}

Seeds of six indica rice cultivars used in this study (Table 1) provided by Malaysian Nuclear Agency and the experiment was conducted at Molecular biology laboratory of Malaysian Nuclear Agency during December 2016 to January 2017. Seedlings (twelve plants per genotype) grown on plastic grids floated on distilled water in a plastic tank.

Table 1. List of rice cultivars used in this study.

\begin{tabular}{|c|ll|}
\hline SL. No & Name of entry & Source of radiation \\
\hline 1. & MR 219 & Parent \\
\hline 2. & NMR 151 & Gamma source \\
\hline 3. & NMR 152 & Gamma source \\
\hline 4. & ML 3 & Carbon Ione beam \\
\hline 5. & ML 10 & Carbon Ione beam \\
\hline 6. & ML 30 & Carbon Ione beam \\
\hline
\end{tabular}

\section{Isolation of genomic DNA}

For each rice genotype, total genomic DNA was isolated from young leaves of 2 (two) healthy plants which were grown in a greenhouse for 14 days.

\section{DNA extraction}

Genomic DNA extracted from freshly collected leaf tissues, 1-2 mg of freshly collected leaf used here. Chop sample in petri dish with $1 \mathrm{ml} 3 \mathrm{X}$ CTAB Buffer (Doyle and Doyle, 1987) to which $250 \mathrm{ml}$ content [20 mM EDTA + $100 \mathrm{mM}$ Tris$\mathrm{HCl}(\mathrm{pH} 8.0)+1.4 \mathrm{M} \mathrm{NaCl}+3 \% \mathrm{w} / \mathrm{v} \mathrm{CTAB}+1 \%$ $\mathrm{w} / \mathrm{v}$ PVP) stir and heat up to $60^{\circ} \mathrm{C}$ to dissolved the CTAB and autoclaved. Transfer the mixture to
$2 \mathrm{ml}$ round bottom tube with $7 \mathrm{~mm}$ bead. Place on tissue lyser and shake for 2 minutes. Change orientation and shake for another 2 minutes. Pipette about 800- $\mu$ l supernatant to new eppendoft tube. Incubated in a water bath $\left(60^{\circ} \mathrm{C}\right)$ for 10-15 minutes and mix every 5 minutes. Add $0.8 \mathrm{~V}$ of $24: 1$ (chloroform: Isoamylalcohol; 640 $\mu \mathrm{l})$, invert to mixed. Incubated material was then centrifuged (Sigma 1-14, Germany) at 10,000 rpm for 5 minutes. Aqueous phase remaining at the top interfaced with whitish color and contained denatured proteins and carbohydrates. Aqueous layer removed and transferred to new sterilized eppendorf tubes. $0.6 \mathrm{~V}(360 \mu \mathrm{l})$ cold isopropanol was added and gently inverted to mixed well. Centrifuged again it at 12,00o rpm for 5 minutes 
at $4^{\circ} \mathrm{C}$ to collect the DNA pellet by gently remove the supernatant. $100 \mu \mathrm{l}$ of $70 \%$ ethanol added to wash the pellet DNA. Centrifuged again at 12,000 rpm for few minutes and gently removed the supernatant. Dry DNA at and add $100 \mu \mathrm{l}$ TE

\section{DNA precipitating}

For DNA precipitating $10 \mu \mathrm{l} 3 \mathrm{M}$ sodium acetate (1/10V) pH 5.2 added into the extracted DNA and inverted gently to mix well. After that $220 \mu \mathrm{l}$, absolute ethanol (2V) added and gently mixes by inverting the tube and incubated on ice for 30 minute. Centrifuged at 12,000 rpm for 2 minutes at $4^{\circ} \mathrm{C}$ to discard supernatant. After that, we added $100 \mu \mathrm{l} 70 \%$ ethanol to wash the pellet DNA and centrifuge at 12,000 rpm for 2 minutes at $4^{\circ} \mathrm{C}$ temperature. Then the DNA dried at room temperature for 30 minutes. $50 \mu \mathrm{l}$ of TE used to which $100 \mathrm{ml}$ contained (10mM Tris-HCl (pH 8.0) + 1 mM EDTA) to dissolve the DNA and keep at $4^{\circ} \mathrm{C}$ overnight and transfer to $-20^{\circ} \mathrm{C}$ for future use.

dissolve the pellet DNA and store at $-20^{\circ} \mathrm{C}$. DNA concentration and purity were determined by measuring the absorbance of diluted DNA solution using Nano Drop ND-10oo (Thermo Fisher Scientific, USA). The quality of the DNA tested by staining DNA with ethidium bromide, for electrophoresis we used $0.8 \%$ agarose gel at $100 \mathrm{~V}$ for $45 \mathrm{~min}$ in $0.5 \mathrm{X}$ TBE buffer. After that, the image visualized with an ultraviolet transilluminator.

Table 2. Concentration of sample DNA used in this study.

\begin{tabular}{|lcc|}
\hline Sample & $260 / 280$ & Concentration $(\mathrm{ng} / \mu \mathrm{l})$ \\
\hline MR219 & 2.05 & 68.55 \\
\hline NMR151 & 2.00 & 24.10 \\
\hline NMR152 & 2.09 & 262.35 \\
\hline ML3 & 2.14 & 30.35 \\
\hline ML10 & 1.97 & 52.35 \\
\hline ML30 & 2.09 & 212.15 \\
\hline
\end{tabular}

No agronomic data collected here; only young seedling used for DNA isolation. To perform PCR amplification, you need to combine all the components required for DNA replication.

\section{Primers}

A primer is a short, single-stranded piece of DNA that anneals (attaches) to its complementary sequence on the template. A pair of primers will bind to either side of the target DNA segment providing initiation sites for DNA synthesis. The two primers used in a PCR often designated by the terms forward and reverse. List of various primer used in this experiment given below:

Table 3. List and sequence of primer used in this study.

\begin{tabular}{|c|c|c|c|}
\hline Primer & Sequence & Primer & Sequence \\
\hline OPC-01 & TTCGAGCCAG & OPD-01 & ACCGCGAAGG \\
\hline OPC-02 & GTGAGGCGTC & OPD-02 & GGACCCAACC \\
\hline OPC-03 & GGGGGTCTTT & OPD-03 & GTCGCCGTCA \\
\hline OPC-04 & CCGCATCTAC & OPD-04 & TCTGGTGAG \\
\hline OPC-05 & GATGACCGCC & OPD-05 & TGAGCGGACA \\
\hline OPC-06 & GAACGGACTC & OPD-06 & ACCTGAACG \\
\hline OPC-07 & GTCCCGACGA & OPD-07 & TTGGCACGGG \\
\hline OPC-08 & TGGACCGGTG & OPD-o8 & GTGTGCCCCA \\
\hline OPC-09 & CTCACCGTCC & OPD-09 & CTCTGGAGAC \\
\hline OPC-10 & TGTCTGGGTG & OPD-10 & GGTCTACACC \\
\hline OPC-11 & AAAGCTGCGG & OPD-11 & AGCGCCATTG \\
\hline OPC-12 & TGTCATCCCC & OPD-12 & CACCGTATCC \\
\hline OPC-13 & AAGCCTCGTC & OPD- 13 & GGGGTGACGA \\
\hline OPC-14 & TGCGTGCTTG & OPD-14 & CTTCCCCAAG \\
\hline OPC-15 & GACGGATCAG & OPD-15 & CATCCGTGCT \\
\hline
\end{tabular}




\section{Results and Discussion}

Although PCR is a powerful tool for the amplification of genetic sequences, it is not an exact science. Sometimes, even though using an established PCR protocol that had been optimized and successful for the amplification of a particular DNA segment, use of that same protocol on a different region can result in a less than desirable outcome.

In order to optimize the RAPD technique for rice, various number of PCR cycle and several concentrations of $\mathrm{MgCl}_{2}$ were tested, maintaining constant the concentrations of each dNTPs and PCR reaction buffer, and Taq DNA polymerase. The concentration and other parameters selected based on the production of highest number and intensity of bands.

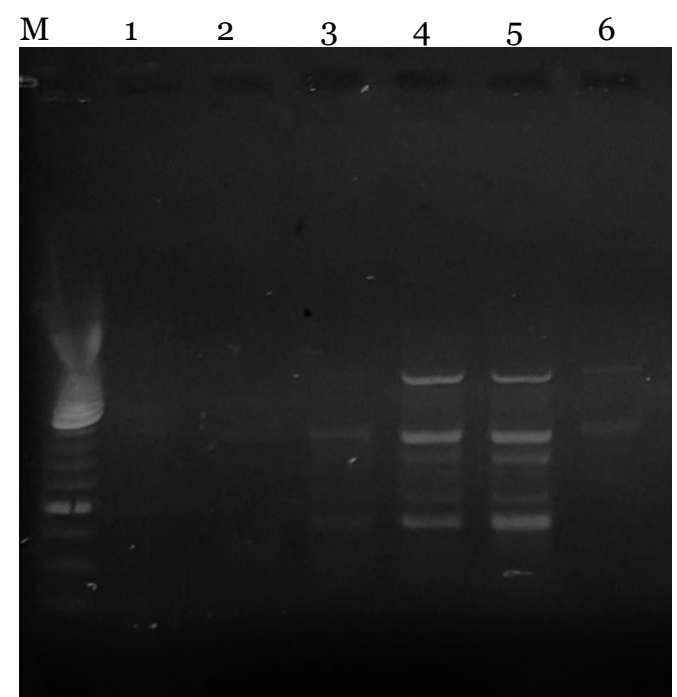

a)

\section{PCR Cycle Optimization}

The Polymerase Chain Reaction (PCR) is a powerful technique used for the amplification of a specific segment of a nucleic acid. PCR steps of denaturation, annealing, and extension repeated (cycled) many times to amplify the target DNA. Starting with only a very small amount of material, a DNA segment can multiplied by over a million-fold. Using inappropriate PCR cycles can lead to insufficient amplification. The number of cycles required for amplification depends on the number of copies of template DNA present at the beginning of the reaction.

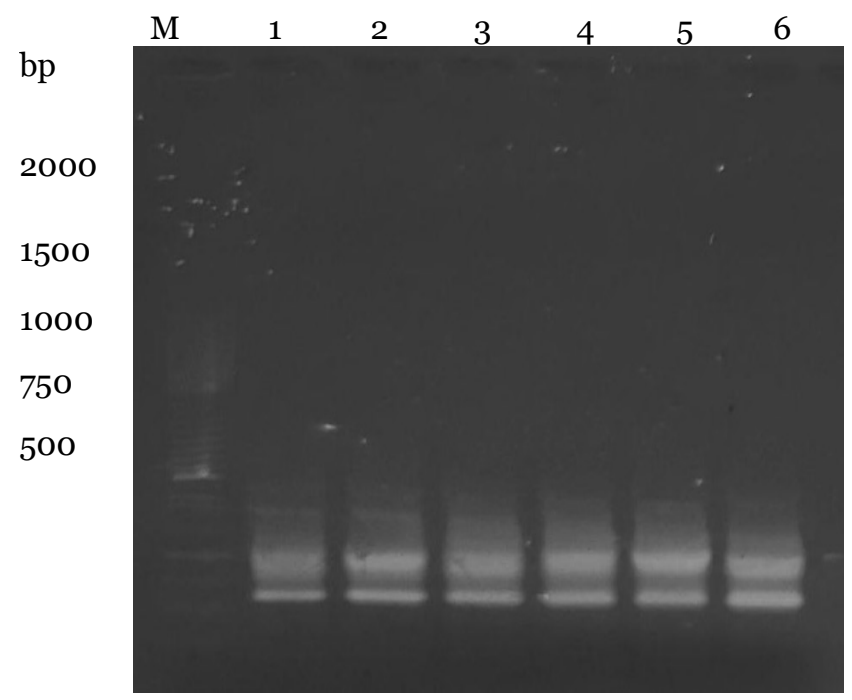

b)

Fig. 1. RAPD profiles obtain from a) 30 PCR cycles and b) 50 PCR cycles, Lane 1 (MR 219), Lane 2 (NMR 151), Lane 3 (NMR 152), Lane 4 (ML 3), Lane 5 (ML 10), Lane 6 (ML 30) M are the size markers used (Molecular Weight Marker 100 base pair Promega, USA).

The number of cycles usually carried out 25-35 times. If we consider the Fig. 1, we find that band produced at 30 cycles is not enough to understand, where at 50 cycles it was not enough clear to separate one band from other. In a typical PCR, the maximum amount of product is approx. $10^{12}$ copies of the template. Starting from one copy, the most efficient PCR would reach this level in 40 cycles. If the DNA input is fewer than up to 40 cycles may be required to produce a sufficient yield. More than 45 cycles not recommended as non-specific bands start to appear with higher numbers of cycles. Like this study (Jorge et al., 2005) indicate that like other factors number of thermal cycles also affects the reproducibility of band.

\section{$\mathrm{MgCl}_{2}$ Concentration}

Magnesium ion concentration is a critical element in determining the performance of amplification reaction and significantly varied the profiles produced. Low magnesium ion concentration results in poor reaction efficiency, while high concentration results in poor reaction specificity (Persing et al., 1993). 


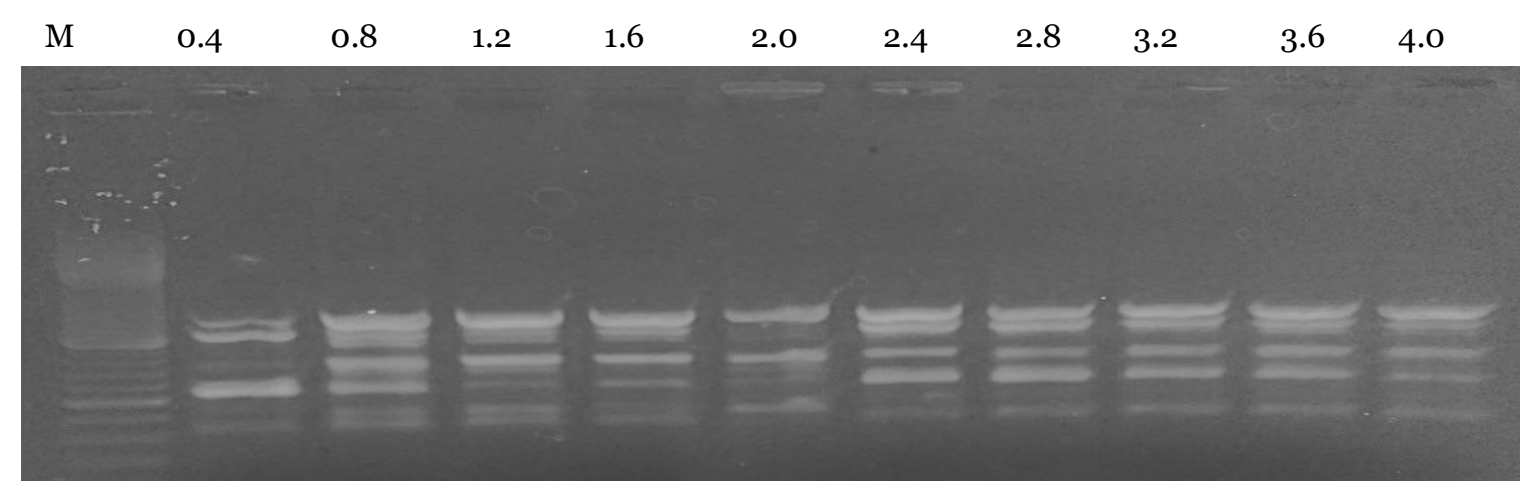

Fig. 2. RAPD profiles obtain from various $\mathrm{MgCl}_{2}$ concentrations but using same DNA template.

We were working with nonspecific primer template interaction we expected that increasing the concentration of magnesium ion had the net effect of decreasing the stringency of primer binding. Surprisingly, a notorious lack of bands was noticed when using $3.0 \mathrm{mM} \mathrm{MgCl}_{2}$ and the best performance occurred at a lower concentration, 2.0 $\mathrm{mM} \quad \mathrm{MgCl}_{2}$ (Fig. 2). Magnesium ions interact with the DNA polymerase enzyme during this process. Magnesium, in fact, is required for DNA polymerase activity. Because of the close relationship between these molecules, magnesium said to be a cofactor of the polymerase enzyme. PCR amplification of a DNA target would not occur if magnesium left out of the reaction. Lower $(0.4,0.8,1.2$ and $1.6 \mathrm{mM})$ and higher $(2.0,2.4,2.8,3.2,3.6$ and $4.0 \mathrm{mM})$ $\mathrm{MgCl}_{2}$ concentrations produced fewer and non- specific bands. In our experiment, the $1.6 \mathrm{mM}$ $\mathrm{MgCl}_{2}$ was ideal to amplify the rice DNA. For RAPD optimization in rice (Kanawapee et al., 2011) also used near about similar concentration of $\mathrm{MgCl}_{2}$.

\section{Primer optimization}

For primer optimization, sixteen different RAPD primers tested here. Among them four RAPD primers $\left(\mathrm{CO}_{2}, \mathrm{CO}_{3}, \mathrm{CO}_{4}\right.$, and $\left.\mathrm{CO} 6\right)$ were discriminatory based on the intensity of amplified RAPD bands and less smear formation (Fig. 3). Some of them not able to produced band with listed primer. All the primers cited above produced different RAPD fragment patterns. The number of fragments generated per primer varied between zeros to eight.

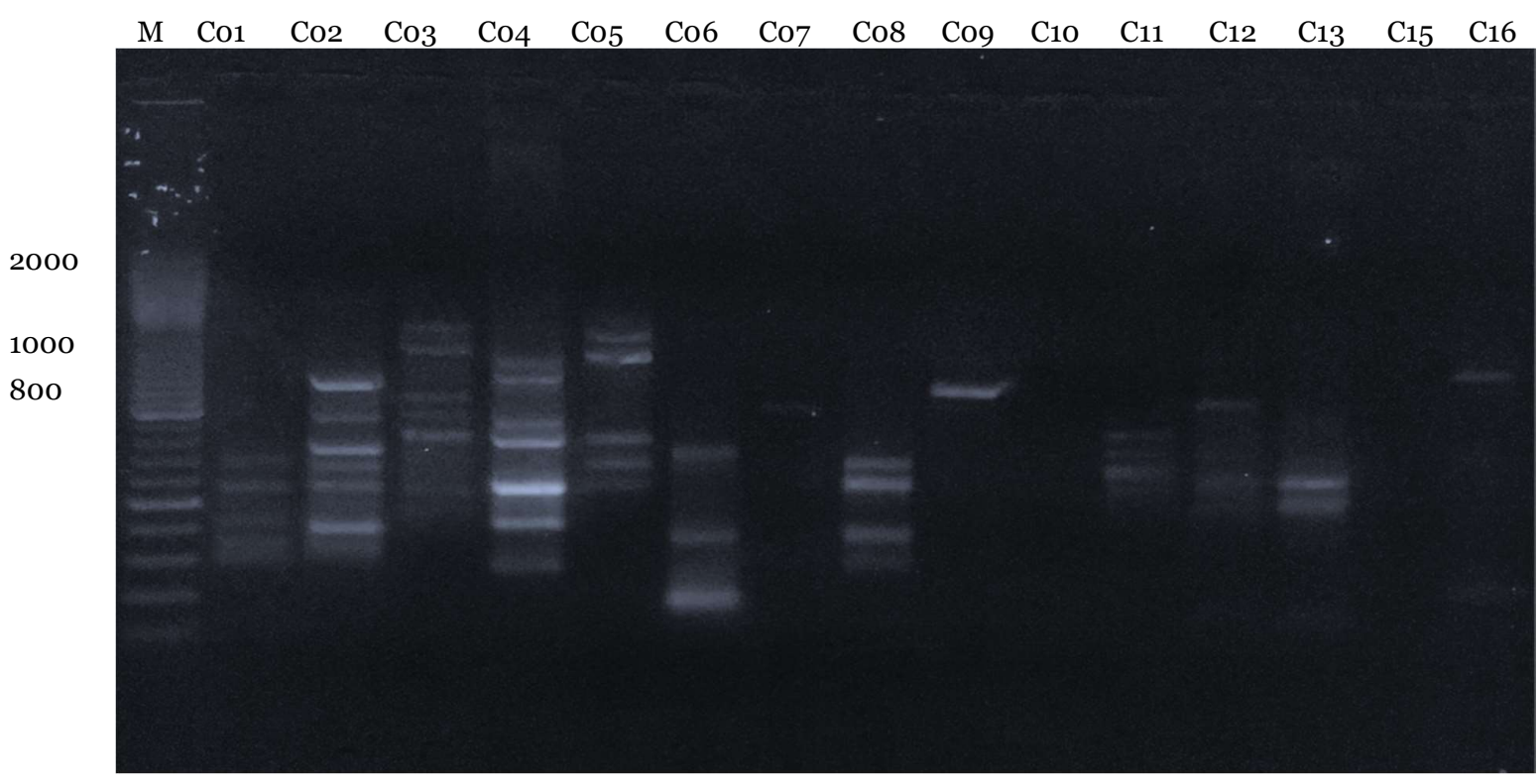

Fig. 3. RAPD profiles obtain from using various primers at same DNA template. 
To conduce RAPD experiments for the rice species it was established the following reaction conditions for the final volume of $20 \mu \mathrm{l}$ where 0.1 unit of Taq DNA polymerase, $0.4 \mu \mathrm{l}$ of each
dNTP, $2.5 \mathrm{mM} \mathrm{MgCl}_{2}, 1 \mu \mathrm{l}$ primer and $2.0 \mu \mathrm{l}$ of DNA template.

Table 4. Sequence of selected RAPD primer KITS (Euro fins Genomic).

\begin{tabular}{|c|c|c|}
\hline Rapd kit & Primer & Sequence \\
\hline \multirow[t]{6}{*}{ KIT C } & OPC-02 & GTGAGGCGTC \\
\hline & OPC-03 & GGGGGTCTTT \\
\hline & OPC-04 & CCGCATCTAC \\
\hline & OPC-05 & GATGACCGCC \\
\hline & OPC-06 & GAACGGACTC \\
\hline & OPC-08 & TGGACCGGTG \\
\hline \multirow[t]{2}{*}{ KIT D } & OPD-02 & GGACCCAACC \\
\hline & OPD-03 & GTCGCCGTCA \\
\hline
\end{tabular}

After amplification conditions were established, six samples performed with the primers $\mathrm{CO} 2$ and $\mathrm{CO} 4$. All the primers cited above produced different RAPD fragment patterns. The number of fragments generated per primer varied from four to eight. 3.1 per individual for $\mathrm{CO} 2$ and 2.9 for $\mathrm{CO}_{4}$ from a total of twenty three and seventeen scorable bands, respectively. Three polymorphic bands with size of approximately $1000 \mathrm{bp}$ to $400 \mathrm{bp}$ were obtained for $\mathrm{Co} 2$ and one polymorphic band with size of approximately 700 bp to $500 \mathrm{bp}$ were obtain form $\mathrm{CO}_{4}$ primers, respectively (Fig. 2). However, used RAPD primers to study genetic difference of seven Egyptian rice genotypes. From this profile Fig. 4, we can easily differentiate the source of radiation as well as the mother variety MR 219 from other. When we consider $\mathrm{CO} 2$ primer then we find that MR 219 produce band nearly equal to 8oobp to 50obp where as other variety NMR 152 and ML 3 produce band nearly equal to $1000 \mathrm{bp}$ to $500 \mathrm{bp}$. $\mathrm{CO} 4$ primer show polymorphism at $600 \mathrm{bp}$ for MR 219, NMR 152 and ML 10. MR 219 produced one clear band at 6oobp region where NMR 151, ML 3 and ML 10.

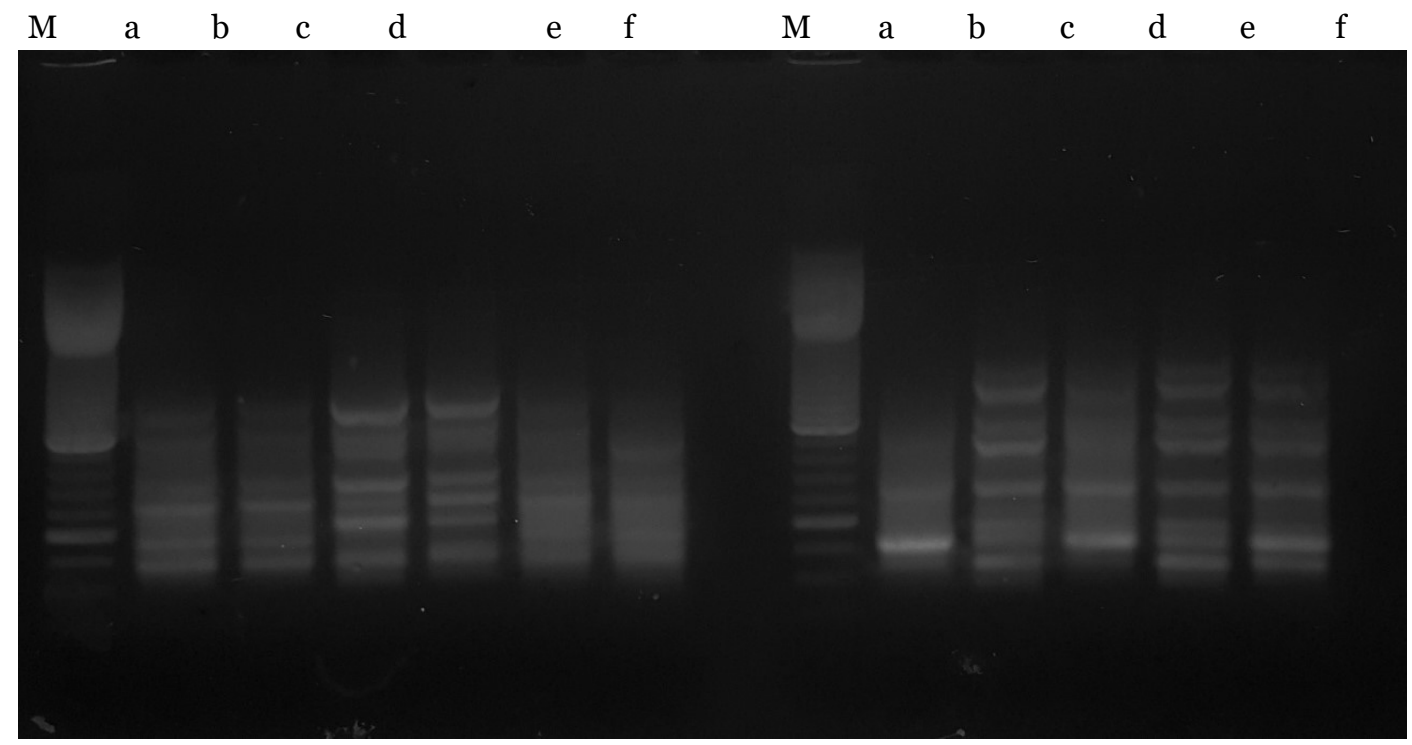

Fig. 4. RAPD profiles obtain used primer a) $\mathrm{CO}_{2}$ (left site) and b) $\mathrm{CO}_{4}$ (right site), Lane a (MR 219), Lane b (NMR 151), Lane c (NMR 152), Lane d (ML 3), Lane e (ML 10), Lane f (ML 30) M are the size markers used (Molecular Weight Marker 100 base pair Promega, USA). 


\section{Conclusion}

From above discussion, it is clear that after mutation the parent MR219 performed some genetic modification and produce genetically different variety namely NMR151, NMR152, ML3, ML10 and ML30. These mutant varieties have two different groups based on their mutation source and it has cleared based of their RAPD profile.

\section{References}

Anumalla, M., Roychowdhury, C.K., Mazid, M. and Rathoure, A.K. 2015. Utilization of plant genetic resources and diversity analysis tools for sustainable crop improvement with special emphasis on rice. Int. J. Adv. Res. 3(3): 1155-1175.

Choudhury, P.R., Kohli, S., Srinivasan, K., Mohapatra, T. and Sharma, R.P. 2001. Identification and classification of aromatic rices based on DNA fingerprinting. Euphytica. 118(3): 243-251.

Doyle, J.J. and Doyle, J.L. 1987. A rapid DNA isolation procedure for small quantities of fresh leaf tissue. Phytochem. Bull. 19: 11-15.

Haussmann, B.I.G., Parzies, H.K., Presterl, T., Susic, Z. and Miedaner, T. 2004. Plant genetic resources in crop improvement. Plant Gen. Res. 2(1): 3-21.

https://www.statista.com/topics/1443/rice

Jorge, F., Jinnay, R., Omar, F., Ayme F.C. and Mayda, C. 2005. Optimization of random amplified polymorphic DNA techniques for use in genetic studies of cuban triatominae.
Rev. Inst. Med. Trop. S. Paulo. 47(5): 295300.

Kanawapee, N., Sanitchon, J., Srihaban, P. and Theerakulpisu, P. 2011. Genetic diversity analysis of rice cultivars (Oryza sativa L.) differing in salinity tolerance based on RAPD and SSR markers. Electronic $J$. Biotech. 14(6): 213-218.

Persing, D.H., Smith, T.F., Tenover, F.C. and White, T.J. 1993. Diagnostic Molecular Microbiology: Principles and Applications, Washington. pp. 88-103.

Ravi, M., Geethanjali, S., Sameeyafarheen, F. and Maheswaran, M. 2003. Molecular marker based genetic diversity analysis in rice (Oryza sativa L.) using RAPD and SSR markers. Euphytica. 133(2): 243-252.

Virk, P.S., Ford-Lloyd, B.V., Jackson, M.T., Pooni, H.S., Clemeno, T.P. and Newbury, H.J. 1996. Predicting quantitative variation within rice germplasm using molecular markers. Heredity. 76(3): 296-304.

Virk, P.S., Newbury, H.J., Jackson, M.T. and Ford-Lloyd, B.V. 1995. The identification of duplicate accessions within a rice germplasm collection using RAPD analysis. Theor. Appl. Gen. 90(7-8): 1049-1055. https://doi.org/10.1007/BFo0222920.

Williams, K., Kubelik, A., Livak, K., Rafalski, J. and Tingey, V. 1990. DNA polymorphisms amplified by arbitrary primers are useful as genetic markers. Nucleic Acids Res. 18(22): 6531-6535. 